\title{
1st International Symposium for ICS \& SCADA Cyber Security Research 2013 (ICS-CSR 2013)
}

\author{
Leicester, UK \\ 16-17 September 2013
}

Editors

Dr Helge Janicke

Dr Kevin Jones 


\section{Abstract}

The 1st International Symposium for Industrial Control System \& SCADA Cyber Security Research (ICSCSR) brings together researchers with an interest in the security of industrial control systems in the light of their increasing exposure to cyber-space. The topics of interests are broad, ranging from security for hardware/firmware used in industrial control systems, to system aspects of ICS such as secure architectures and vulnerability screening, to the human aspects of cyber security such as behaviour modelling and training. ICS-CSR is a research conference aimed at high quality academic research in the cyber security of industrial control system from the hardware, system and human-factor perspectives.

\section{Sponsors}
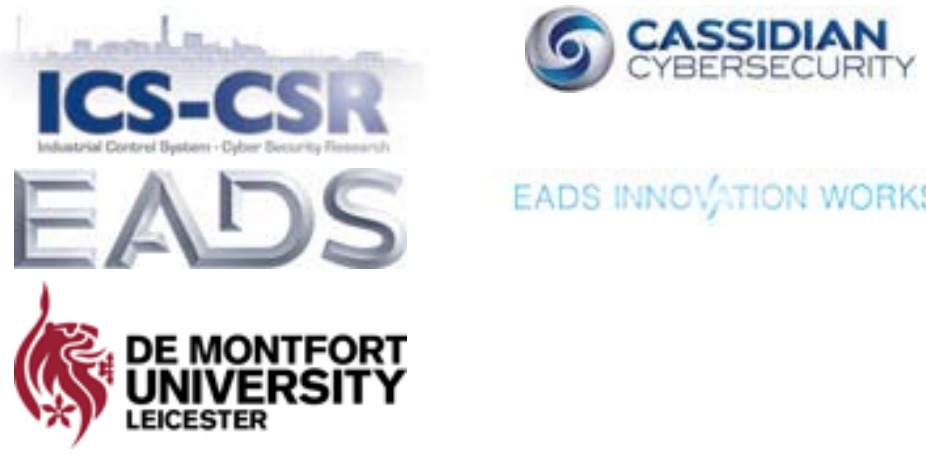

EADS INNOV/ATION WORKS 


\section{Full Synopsis}

The 1st International Symposium for Industrial Control System \& SCADA Cyber Security Research (ICSCSR) brings together researchers with an interest in the security of industrial control systems in the light of their increasing exposure to cyber-space. The topics of interests are broad, ranging from security for hardware/firmware used in industrial control systems, to system aspects of ICS such as secure architectures and vulnerability screening to the human aspects of cyber security such as behaviour modelling and training. ICS-CSR is a research conference aimed at high quality academic research in the cyber security of industrial control system from the hardware, system and human-factor perspectives.

We are delighted to have a number of very exciting and interesting contributions to this year's event ranging from threat analysis work to detailed technical advances made in the field. In particular we are looking forward to two very distinguished keynote speakers to address you during the event. Dr Sally Leivesley (Newrisk) will update you on the technical and human aspects of cyber terrorism and Thomas Brandstetter (Fachhochschule St. Pölten) will revisit the current state of play in the aftermath of Stuxnet.

We would like to thank EADS-Cassidian and EADS Innovation Works for sponsoring this event. A particular thank you to all the members of our programme committee for providing so timely and excellent reviews of the submissions, the local organisers at De Montfort University and of course the dedicated authors for submitting their work to this event. 


\section{Editors}

This conference was edited by:

Dr Helge Janicke obtained his PhD in Computer Security in 2007 (De Montfort University). Helge is working on formal models of security, in particular dynamic access control policies and security aspects that require the modelling of system security behaviours. Helge is leading the Computer Security and Trust Research Theme in DMU's Software Technology Research Laboratory (STRL) and has published his research widely at internationally renowned journals and conferences.

Dr Kevin Jones is the Research Team Lead for EADS Innovation Works Cyber Operations. He is active in the cyber security research community and holds a number of patents within the domain. He has many years' experience in consultancy to aid organisations in achieving accreditation to ISO27001 Standard on Information Security Management and lecturing in cyber security. Kevin joined EADS in 2011 where he has worked on risk assessments, security architectures, and cyber operations in ICS/SCADA systems and critical national infrastructure (CNI). He is a Member of BCS, IEEE and ISC2 and is accredited as a Certified Information Systems Security Professional (CISSP) and ISO27001 Lead Auditor. 


\section{Papers:}

Amit Soni, Sye Loong Keoh, Sandeep S. Kumar \& Oscar Garcia-Morchon

HADA: Hybrid Access

Decision Architecture for Building Automation and Control Systems

http://dx.doi.org/10.14236/ewic/ICSCSR2013.1

Tina Wu, Jules Ferdinand Pagna Disso, Kevin Jones \& Adrian Campos Towards a SCADA Forensics

Architecture $\quad$ http://dx.doi.org/10.14236/ewic/lCSCSR2013.2

Thomas H. Morris \& Wei Gao Industrial Control System Cyber Attacks

http://dx.doi.org/10.14236/ewic/ICSCSR2013.3

Michael Robinson The SCADA Threat Landscape http://dx.doi.org/10.14236/ewic/ICSCSR2013.4

Professor Andrew John Charles Blyth, PhD Role Logic and its Application to the Analysis of Process Control Systems from the Socio - Technical System Perspective http://dx.doi.org/10.14236/ewic/lCSCSR2013.5

Khan Ferdous Wahid, Nicolai Kuntze \& Carsten Rudolph Trusted Virtual Machine Management for Virtualization in Critical Environments http://dx.doi.org/10.14236/ewic/ICSCSR2013.6

Andrew Nicholson, Helge Janicke \& Tim Watson An Initial Investigation into Attribution in SCADA Systems $\quad$ http://dx.doi.org/10.14236/ewic/lCSCSR2013.7

Ivan Cibrario Bertolotti, Luca Durante, Tingting Hu \& Adriano Valenzano A Model for the Analysis of Security Policies in Industrial Networks http://dx.doi.org/10.14236/ewic/ICSCSR2013.8

Robert Oates, Fran Thom \& Graham Herries Security-Aware, Model-Based Systems Engineering with SysML http://dx.doi.org/10.14236/ewic/ICSCSR2013.9

Antoine Lemay, José Fernandez \& Scott Knight An isolated virtual cluster for SCADA network security research $\quad$ http://dx.doi.org/10.14236/ewic/ICSCSR2013.10

Emmanouil Vasilomanolakis, Mathias Fischer \& Max Mühläuser Collaborative Intrusion Detection in Smart Energy Grids http://dx.doi.org/10.14236/ewic/ICSCSR2013.11

S.L.P. Yasakethu \& J. Jiang Intrusion Detection via Machine Learning for SCADA System Protection http://dx.doi.org/10.14236/ewic/ICSCSR2013.12

William Knowles, Daniel Prince, David Hutchinson, Jules Ferdinand Pagna Disso \& Kevin Jones Towards Real-Time Assessment of Industrial Control Systems (ICSs): A Framework for Future Research $\quad$ http://dx.doi.org/10.14236/ewic/ICSCSR2013.13 